\title{
Computers in Schools in the USA: A Social History
}

\author{
Kevin R. Parker ${ }^{1}$ and Bill Davey ${ }^{2}$ \\ ${ }^{1}$ Idaho State University, USA \\ ${ }^{2}$ RMIT University, Australia \\ Parkerkr@isu.edu, Bill.Davey@RMIT.edu.au
}

\begin{abstract}
This chapter looks at the history of computers in the USA schools from a social history perspective. Instead of concentrating on innovations and leaders the story of mass adoption in schools is told. This history focuses on the 1980 s when the major growth of student numbers and hours of contact with computers became a reality in American schools.
\end{abstract}

Key Words: USA, schools, computers, adoption, social history.

\section{Introduction}

The United States played a pivotal role in the history of computers. Everyone knows of the famous companies such as IBM and of the founders of modern computing such as Grace Hopper. A comparatively early entry to widespread commercial computing in the country should be evident in educational applications. We can be certain that large scale rollouts of educational programs had been established by 1968 as in that year, reports were being published regarding the success of the use of PLATO terminals [1-3]. Despite the certainty of facts supporting this view of history, questions remain: "How widespread were computers in education?" and "what were the real impacts on people's lives from the computer and when did they become real for the ordinary person?" For example the Plato IV terminal, an amazing educational innovation, was around in 1975, but available in 150 locations served by a donated computer. This is a significant number in normal historical terms - it could be described as a successful innovation. However, as 150 locations is a small fraction of the 109,000 schools of the time, the Plato terminal cannot be seen as a socially significant innovation. It clearly led to innovations that were significant but was not so in its own right.

History can be seen as the story of pioneers and new inventions. Another view can be obtained by following the trend of large-scale adoptions. To contrast these views of history consider two educational technologies. In the 1970s the invention of the 'Video Disc' could be seen as an important topic of conversation amongst educators. In hindsight we can see that this invention was superseded by the more flexible multimedia facilities of personal computers. Compare this with an invention that came from military training. The military historian Olsen (1982) recounts the first use of chalk to bring a multimedia experience to the classroom: 
"One of the very first uses of the chalkboard was at West Point in 1817. A Frenchman, Claude Crozet, ex-officer under Napoleon, found himself in a dilemma. He did not speak English and had no textbooks to teach his new science course - so he painted a wall of his classroom black and wrote on it with chalk" [4] p32

We will not proffer evidence of the different impact of these two audio-visual devices, but leave it to the reader to judge the social impact of chalkboards versus Video discs. The one of greatest importance to the social historian is that which has the most impact, in this case on schools.

This chapter uses surveys of computer use to draw a picture of the social history of computers in schools in the USA.

\section{An Educational Timeline}

\subsection{Computer Presence}

The computer history museum (2014) notes that IBM had $81 \%$ of the computer market in 1961 and that Xerox PARC opened in 1970, the same year as the creation of ARPANET. A number of personal computers were released by their US manufacturers in 1977, including the famous Apple][. These momentous impacts on society created a feverish climate of innovation in many schools. To translate this story of innovation into a story of the social history of computers in schools requires some information about the spread of computing into large numbers of schools and the impact on the general population of schools. The question to be answered is: when did computers become significant in the school system?

A traditional history answer would put the beginnings somewhere in the 1950s. Commentators trace the first computers in schools to Federal funding in the 1950s.

"The federal government supported technology for schools as early as the late 1950s, largely through funding from the National Science

Foundation and the Department of Education [5] p7.

The social history answer to the question of beginnings is the year 1983. Detailed surveys of the number and distribution of computers showed that the widespread presence of computers was much later than the early 1950s:

"Between mid-1981 and the fall of 1983, the percentage of elementary schools with one or more microcomputers jumped from 10 percent to over 60 percent. During that same period, the percentage of secondary schools with five or more microcomputers grew from 10 percent to well over 50 percent" [6] p23.

Surveys of computer penetration into schools have been continually performed in the United States. The Federal Government is concerned with equity and so considerable effort is put into measuring equity in a number of areas and computer use has been one of those areas for many years. Much of this focus is 'Title I' which provides for (amongst many other requirements):

“... distributing and targeting resources sufficiently to make a difference to local educational agencies and schools where needs are greatest” [7]. 
The existence of Title I as a federal charter has had a significant influence on the penetration of computers into schools. The charter acts as both a basis for audits of the education system but also as a source of funding directed at those schools where resources would not normally be available for the purchase of computers and training of teachers. The 2,000 NSBA report attributes Title I funds as the basis of computer purchases in most eligible schools;

"Title I represents an important source of funding for this technological expansion. Indeed, Title I funds have paid for a significant portion of the computers now in use in high-poverty schools." [8] p76

The cumulative effect of these funding programs produced a fairly uniform presence of computers across the country. A study in 1997 produced an illuminating picture of the precipitous growth of computers and sets a maturity level around the year 1990 in terms of real student access.

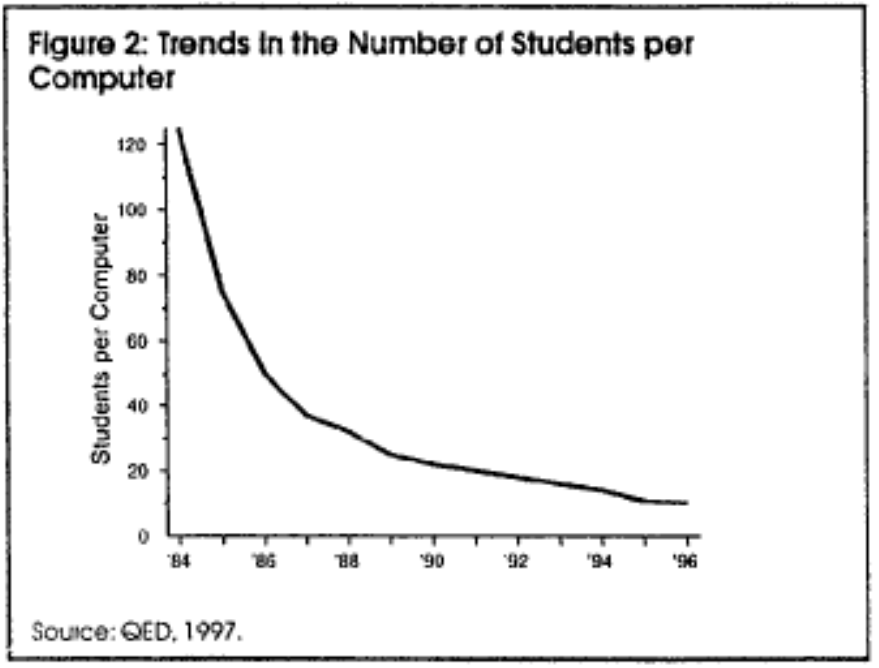

Fig. 1. Taken from [5] p13

A contemporary critic of educational computer use disputes that the presence of computers should be taken as a sign of impact. He would set 1991 as a more appropriate year of beginning on the basis of the percentage of schools with computers, student ratios and number of hours of use in a day.

"As an innovation, school use of computers has spread swiftly, widely, and, on occasion, deeply. But the picture is clouded. A few statistics on computer use suggest the broad outlines of the picture. In 1981, 18 percent of schools had computers; in 1991, 98 percent had them. In 1981, 16 percent of schools used computers for instructional purposes; by 1991, 98 percent did so. In 1981, there were, on average, 125 students per computer; in 1991, there were 18. In 1985, students used computers in school labs just over 3 hours a day; in 1989, that figure had risen to 4 hours a day." [9] p186 
This opinion is consistent with surveys conducted by Becker (1984) who found that the jump in computer numbers was not reflected by generous time allocations to students. He conducted surveys in 1983 and 1984 and found:

“... during an average week, only about one-eighth of the students in elementary schools that owned microcomputers had an opportunity to use one. More significantly, the students who did use a microcomputer spent on the average only 20 minutes at the computer during the week, some of this in a paired or group situation." [6] p27

It seems that there might be two social beginning dates for computer presence: circa 1983 when most schools had some computers and circa 1991 when students had some level of real access to computer time.

\section{Computing as an Idea}

The argument that computers were not present in classrooms until 1983 or perhaps 1991 does not necessarily disprove their influence. Clearly the US Government was influenced in terms of education policy from the late 1950s. There is some evidence that this was mostly a convincing argument for the use of computers to monitor schools and make efficiency gains in administration, as had been happening with most departments since Hollerith and the census.

A telling sign that the influence of computers in education was not just a government concern was the burgeoning industry growing around educational computing. Becker [6] noted that there were at least six nationally circulated monthly publications on the subject targeted at schoolteachers and administrators. Several important thinkers were spreading the word. These included Seymour Papert [13] who saw that students could find a learning environment in the computer rather than an object of study or a vocational topic. At the same time people like Alan Kay [14] were working on educational hardware and programming systems (in this case the prescient Dynabook and Smalltalk). Each of these innovative streams in computer education was collecting adherents.

Computers had become part of the social consciousness. As industrial computer use became widespread a groundswell of interest involved parents. Becker [6] found that a principle concern of parents was the possibility of employment in their children's future being dependent upon the child's ability to work with computers. This feeling in the community is an indication of the social impact of computers in education totally independent on the existence of computers or courses in schools. Of course teachers are not immune from social trends and many were aware of the computer as an industrial fact even though their school had not yet made the move to purchase equipment. This awareness showed in people all around the system trying out the new personal computers, reading the flourishing magazines and becoming proselytizers for the value and stimulation of computers, especially in programming. Becker [6] points to this trend and the phenomenon of mathematics teachers leading the way: 
"Many teachers and school administrators fear that they, too, need to know something about how to use computers. A number who have tried programming or using computer programs on their own find it intellectually stimulating and possibly even cost-effective. Like adventurous computerists in other professional domains, many become proselytizers for their use by others in their workplace. This happens first and most often in high schools and among mathematics teachers, for whom computers, as objects to be programmed, are most easily integrated into other instructional responsibilities" [6, p23].

The availability of personal computers (sometimes called microcomputers because of the integrated circuit based affordable systems that came onto the market) were also a social phenomenon. A magazine of the time, Creative Computing, is available online (https://archive.org/details /creativecomputing). This magazine was published from 1974 until 1985 and is typical of magazines of the time, but with a heavy emphasis on educational and hobby computing. Skimming any set of issues shows that topics in the education section included regular articles on interesting programs to write, use of calculators in the classroom, computers to build from kits and reviews of computers. By 1980 the magazine had become mostly hobby oriented but with continued support for the programmer. (An interesting advertisement in the Winter of 1982, was for the 'new' 10 megabyte Winchester hard disc for a mere \$3,095 1982 dollars!). Eventually the magazine turned to support for small business computing but could not remain viable in this market. The diffusion of educational computing through publications was mirrored by other commercial evidence. Becker [6] noted that there were more than 5,000 computer programs for classroom use in a 1983 catalogue. This tells of enormous amounts of energy being put into an education market well before the majority of schools had even one computer.

The existence of enthusiastic teachers, publications and an energetic educational software industry cannot be put into a social context as there is little evidence of the proportion of people in the relevant community. That the community was energetic is beyond doubt, that it formed a majority of people in schools is yet to be supported. The length of time in which the computer became entrenched in schools is very short. By 1998, a short 15 years after one of the 'social beginnings' of 1983 postulated above, the general public had become convinced of the value of computers in schools.

"An MCI nationwide poll in 1998 found that nearly 60\% of the public answered 'a great amount' when asked 'How much do you think computers have helped improve student learning?'” [10, p2].

\section{The Problems of a New Technology}

As argued above the existence of computer hardware in schools by 1983 was at significant levels. The rationale for computers being there was not quite so clear cut. Parents wanted employment outcomes, educational thinkers like Papert and Kay had clear ideas of what could be done in classrooms, teacher enthusiasts had become intrigued by the attraction of programming, but the existence of one computer in a school amongst many untrained teachers did not ensure a school with a clear educational imperative. Becker [6] saw this as a significant problem: 
"With such a sudden emergence of 'computers' in the instructional repertoire of schools, it is not surprising that an intellectual and empirical rationale for their educational value has barely begun to develop" [6, p26]

The lack of a clear direction in many schools meant that hardware purchases blossomed in the first years after 1983, but some commentators saw a lesser increase in the useful purpose for all those computers. One telling commentary on actual classroom use from as late as 1993 suggested that the computer had not achieved general acceptance as an educational tool:

"The overall picture, however, after the introduction of the personal computer a decade ago and persistent efforts to improve schooling, suggests at best that computers are an expanding but marginal activity in schools with wide variation in administrator, teacher, and student use. A one-line caption for all of this activity over the last decade is: Computers meet classroom; classroom wins" [9].

The cause of this perception of failure to maximize the potential of school computers is often illustrated by a quote from Thomas Edison:

"The motion picture is destined to revolutionize our educational system and... in a few years it will supplant largely, if not entirely, the use of textbooks." Thomas Edison, 1922.

The point being made is that computers are no different from other technologies that have been brought to the classroom and the inevitable outcome is that the technology will fade into the background and that this is evident by 1995 .

An alternative explanation of slow uptake in the classroom is an infrastructure argument. A much later survey in 1997 shows the retrospective picture of the classrooms of the early years. The Educational Testing Service from Princeton conducted a study of schools in the country for the 1995/6 school year [5]. This can be considered to be at the very end of the widespread introduction of computers. Problems found in this study can be assumed to have existed for the previous decade and give a stark view of missing infrastructure. Relevant findings included:

- Only $15 \%$ of teachers had at least nine hours of training in educational technology

- 18 States did not require educational technology courses for a teaching license

- While $85 \%$ of schools had multimedia computers the average ratio of students was 24 students to 1 computer, nearly five times that recommended

- Only 6 to 8 percent of available courseware was judged as 'exemplary' and less than half was good enough to warrant a review.

These findings indicate that computers in schools suffered from poor teacher training, high numbers of students trying to use the equipment and poor software.

\section{The Educational Computing Debates}

One of the purposes of schooling is to prepare students to perform in their society. As the United States became more computerized an obvious need arose for preparation in computing. This is an obvious reason for exposing students to computers: when they 
leave school they need to be able to interact with the computers all around them. This made the task of those asking for funds relatively easy. Computers could be a gadget like the film projector, but they were also the stuff of commerce and students needed to use them.

"Because of the widespread and growing use of such technology in both the home and the workplace, computer equipment is unlikely to end up in closets or even to sit idle most of the time. Hence, for both students and teachers, there is a kind of 'authenticity' associated with using this equipment; for students, the technology represents the future" [11] p32

One of the earliest educational computing projects to gain significant funding was the Plato system [1-3]. These systems were largely used for computer aided instruction (CAI), often in military training or in colleges. As a result of this exemplar many people justifying computers for their schools did so on the basis of teaching about computers (computer literacy) or as tools for efficient learning through CAI:

"There is little consensus about how computers should be integrated into school curricula in the U.S. Some argue that they should be used to teach 'computer literacy' (Winkle and Mathews, 1982), and often tacitly identify 'computer literacy' with programming skills and knowledge about the workings of computers. Others emphasize the special role that computer based systems can play as instructional aids, but people vary considerably in their views. Some valuing drill and practice in existing curricula. Others find drill and practice thoroughly pedestrian, and argue for more progressive, discovery-oriented learning in richer, student driven computerized environments" [12].

Among those using this line of argument were those advocating computer use as a tool common in business, as a tool for learning management or as a tool for motivating students:

"Computer technology can be used in the classroom in three ways: 1) as tools such as word processors, spreadsheets, programming languages, and electronic network systems; 2) as integrated learning systems that present exercises for students to work on individually and that keep records of student progress for reporting to the teacher; and 3) as simulations and games that engage students in computer-based activities designed to be motivating and educational." [11, p29].

These debates were influenced by some very strident educationalists bent on restructuring schools in a new, student centred, non-didactic model of education. Principal among these was Seymour Papert who created the Logo language and the ancillary environment to demonstrate how mathematics might be taught in a new way in which students investigated on their own.

"The phrase 'technology and education' usually means inventing new gadgets to teach the same old stuff in a thinly disguised version of the same old way. Moreover, if the gadgets are computers, the same old teaching becomes incredibly more expensive and biased towards its dullest parts, namely the kind of rote learning in which measurable results can be obtained by treating the children like pigeons in a Skinner box.” [13] p247. 
Also in this camp was Alan Kay, of the Learning Research Group at the Xerox Palo Alto Research Center. Kay saw a chance to use computers to provide a learning environment in which students might experiment and so learn. His vision included a student using the environment in unexpected ways:

- "to provide exceptional freedom of access so kids can spend a lot of time probing for details, searching for a personal key to understanding processes they use daily; and

- to study the unanticipated use of the Dynabook and Smalltalk by children in all age groups." [14, P41].

From the viewpoint of social history these streams of educational thought are confined to the small community of educational thinkers rather than the broader school community at the times being considered. A study of the modern curriculum statements would be required to see if the ideas have spread into the general community.

\section{Conclusion}

Stories from the 1950 s to the 1990 s show that American schooling was rich in innovation from the beginnings of general purpose computing. Brilliant educational thinkers and technologists produced programming environments and hardware platforms that stand up to modern equivalents. The Plato terminal with its touch screen and well written courseware was found to be roughly equivalent to a human teacher, if a little more expensive. The Dynabook and Smalltalk system seem very similar to the modern notebook or tablet, and the Logo system is still in use today.

These amazing experiments in educational computing are historically important but are only precursors of the social history of school computing in the United States. It was not until Title I funding and the momentum of teacher enthusiasts became widespread that the social history involving all schools can be said to have started, and that can be dated to around 1983. It can be argued that the social history of educational computing not involving the actual use of computers predates 1983 as there is a broad evidence base that people around education were being influenced to a great degree prior to the widespread use of the hardware.

The social history of computers in schools is a story of faith in a new technology that came well in advance of sure knowledge of the best use. Debate raged at all levels of the education system regarding the best use. This debate asked school planners to choose between views of how a computer should be used, including using a computer in the school to:

- Teach about computers to prepare students for a technology dominated workplace

- Provide an interactive tool to provide an environment in which students can experiment and learn by doing.

- To provide a resource to increase the productivity of teaching (e.g. CAI)

An interesting recent trend in school computing has been the massive swing towards use of the Internet by schools. This may be a clue to the outcome of the debates on how computers are best used and is certainly a rich topic for further research. 


\section{References}

[1] Blitzer, D.L., Skaperdas, D.: Plato IV - An economically viable large-scale computerbased education system. In: National Electronics Conference (1968)

[2] Smith, S., Sherwood, B.: Educational uses of the PLATO computer system. Science 192, 344-352 (1976)

[3] Plato Learning. History of Plato Learning (February 2004), http://www.plato.com/aboutus / company_history.asp

[4] Olsen, J.R., Bass, V.B.: The application of performance technology in the military: 19601980. Performance \& Instruction 21, 32-36 (1982)

[5] Coley, R., Cradler, J., Engel, P.K.: Computers and Classrooms: The Status of Technology in US, Schools. Educational Testing Service, Princeton (1997)

[6] Becker, H.J.: Computers in schools today: Some basic considerations. American Journal of Education 93, 22-39 (1984)

[7] US Department of Education. Title I - Improving The Academic Achievement of The Disadvantaged (1965),

http: / /www2 .ed.gov/policy/elsec/leg/esea 02/pg1.html

[8] Puma, M.J., Drury, D.W.: Exploring New Directions: Title I in the Year 2000. ERIC (2000)

[9] Cuban, L.: Computers meet classroom: Classroom wins. The Teachers College Record 95, 185-210 (1993)

[10] Anderson, R.E., Ronnkvist, A.: The presence of computers in American schools, Teaching, learning, and computing: 1998 national survey (1999)

[11] Collins, A.: The role of computer technology in restructuring schools. Phi Delta Kappan 73, 28-36 (1991)

[12] Kling, R.: Value conflicts in the deployment of computing applications. In: Proceedings of the ACM 12th Annual Computer Science Conference on SIGCSE Symposium, pp. 67-84 (1984)

[13] Papert, S.: Teaching Children Thinking. Programmed Learning and Educational Technology 9, 245-255 (1972)

[14] Kay, A., Goldberg, A.: Personal dynamic media. Computer 10, 31-41 (1977)

[15] Papert, S.: Mindstorms: Children, computers, and powerful ideas. Basic Books, Inc. (1980)

[16] Goldberg, A., Kay, A.: Teaching smalltalk, Xerox PARC SSL, p. 77 (1977) 